\title{
Analysis of selected results of engine oil tests
}

\author{
Bogdan Landowski ${ }^{1, *}$, Monika Baran ${ }^{1}$ \\ ${ }^{1}$ University of Science and Technology in Bydgoszcz, Faculty of Mechanical Engineering, Al. prof. \\ S. Kaliskiego 7, 85-796 Bydgoszcz, Poland
}

\begin{abstract}
The study presents selected results of viscosity tests performed for different temperatures of lubricating oil with viscosity marked as $5 \mathrm{w} 30$. Viscosity tests of new oil and oil right after being used have been compared. Lubricating oil used in a drive unit of a passenger car was tested. A vehicle in which oil had been changed irregularly was purposefully selected for the tests. Its mileage was over 15-20 thousand kilometers. Upon testing the vehicle mileage was above 265 thousand kilometers. The values of selected characteristics of the analyzed engine oils have been determined including: density, kinematic viscosity and viscosity index. FUNGILAB rotary viscometer was used for measurement of the oil kinematic viscosity.
\end{abstract}

\section{Introduction}

Most road transport means are equipped with internal combustion engines. Combustion engines are drive systems for passenger cars, trucks, coaches, and public transport buses. Engine oils are used to lubricate elements of both spark-ignition and self-ignition engines.

Engine oil is one of the most commonly used operational liquids in vehicles as without it the drive unit would be unable to work properly. Apart from its basic function, a lubricating oil has a number of other functions. Engine oil is also supposed to carry away the heat, seal and clean the engine, protect its metal parts from corrosion and reduce the destructive effect of the drive unit sealings. Monitoring of the oil state in a drive unit can be useful for assessment of its damage and defects [1-2].

One of the most important parameters of lubricating oil is its viscosity. Viscosity is a measure of internal friction between the oil particles moving relative to each other. In order to choose and compare engine oils its dynamic and kinematic viscosity is to be determined [3-4].

Excessive changes in the oil viscosity value can indicate damage of the drive unit and/or its defects. Significantly lower viscosity can indicate the presence of fuel or coolant in it. The content of a coolant can indicate, i.e. a damage to the gasket under the head, whereas the presence of fuel can mean, i.e. lack of tightness in piston rings [1].

Engine oils are part of transport means operational costs [5-6], and their manufacturing and utilization is an ecological issue. Therefore, people involved in transport undertake attempts to extend the vehicle mileage or a different measure of transport task accomplishment between successive oil changes.

In the case of large lubricating systems and a short time (mileage) between particular oil changes, the problem of engine oil related costs is of particular importance. This is a significant expenditure for public bus transport systems [6-7]. Hence, the models of transport means operation processes often include the costs of lubricating agents [6-10].

This study shows selected results of viscosity tests performed for different temperatures of the engine oil with viscosity 5 w30. An attempt was undertaken to simulate the impact of the drive unit state on the engine oil viscosity characteristics. The results of viscosity tests

* Corresponding author: bogdan.landowski@utp.edu.pl 
were compared for unused oil referred to as 'virgin' with oil right after use, referred to as 'used oil'.

\section{Method of tests}

The research object was the so called virgin oil, that is, oil that had not been used yet and a used oil coming from a drive unit of a passenger car with a given mileage and operation time.

The tested oil had been used in a Citroen Berlingo car. The vehicle selection criterion was irregular oil changes, after mileages longer than 15-20 thousand kilometers. At the time of tests the vehicle mileage was over 265 thousand kilometers. One of the objectives was to determine the impact of the engine state, including accumulation of sealing waxes and residue in the engine, on the oil viscosity characteristics.

An error indicator displayed in the vehicle indicating too low oil pressure. Moreover, the drive unit was characterized by excessive noise emission while operating. Virgin oil was introduced into the engine which after travelling $300 \mathrm{~km}$ was poured down. A test sample was taken from this oil. The analyzed vehicle was provided with new engine oil.

The samples were taken while the used oil was being replaced with new oil. The used oil whose temperature was nearly $90^{\circ} \mathrm{C}$, was poured down from the engine to a clean vessel. Before the sample was taken it had been carefully mixed. The volume of the sample was $1000 \mathrm{~cm}^{3}$. Unused oil was kept in a hermetically closed container to protect it from contact with air and contamination which could have a negative effect on the test results.

Glass beakers of $600 \mathrm{ml}$. volume were used to determine the oil density. An empty glass beaker was weighed to determine density of the tested sample and next, it was filled with the analyzed oil up to the volume of $600 \mathrm{~cm}^{3}$ to be weighed again. This was repeated five times. The measurement results were rounded to $0.01 \mathrm{~g}$. On the basis of the measurements made, the density of oil was calculated.

A sample of $600 \mathrm{ml}$ volume was poured into a vessel whose diameter was $97 \mathrm{~cm}$. Viscosity measurement of each oil sample was repeated 5 times, every 10 minutes for each temperature. Kinematic viscosity test was performed with the use of a rotary viscometer FUNGILAB SMART series V210003. The tested liquid was stabilized and did not contain air bubbles [2, 11-12].

Moreover, assessment of the analyzed oils was performed by the method of chromatography. This involved putting a drop of used oil heated to the engine operation temperature on a blotting paper $\left(120-130^{\circ} \mathrm{C}\right)$. This method is used for determination of presence of different impurities in the oil. An analysis involves observing the drop disintegrating into fractions. The colour of the stain nucleus made it possible to determine the amount of residue, the darker it was the more residue there was. A transparent/light yellow crown to be seen around the nucleus indicates fuel content in the tested oil. The diffusion ring width and the comminution level of carbon origin particles in this zone indicate the oil dispersing abilities. Light yellow or transparent border of the stain increases along with decreasing dispersing-washing abilities. The scheme of the stain is presented in figure $1[2]$. 


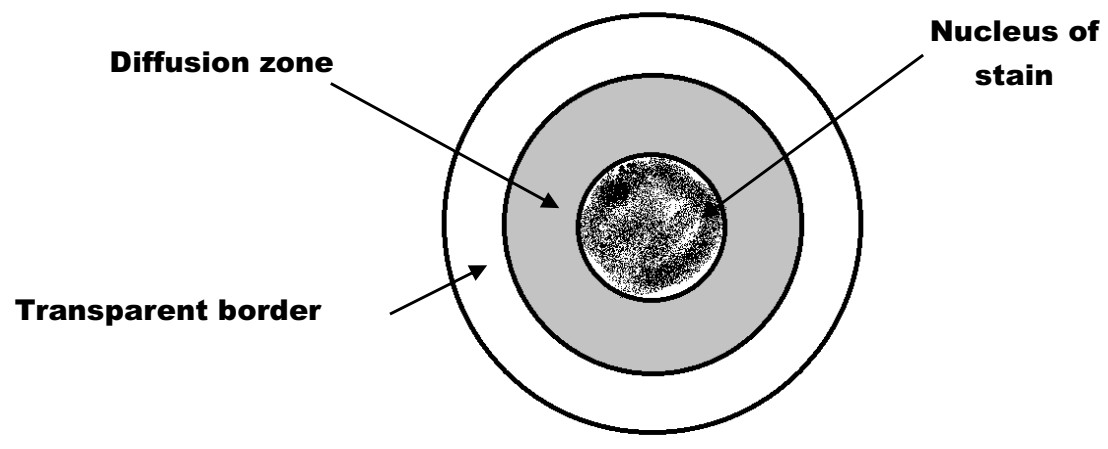

Fig. 1. A scheme of the oil stain on a blotting paper [2, 12].

\section{Selected tests results}

As part of the research, the values of characteristics of the analyzed engine oils including density, kinematic viscosity and viscosity index were determined. Selected results of the tests are presented in tables 1 to 5 and in figure 2 [11-12].

In table 1 there are results of the analyzed sample mass measurements which were later used to estimate density of the oils [11-12].

Table 2 shows the results of the tested oil kinematic viscosity measurements [11-12].

Table 1. Results of measurements of the analyzed sample mass.

\begin{tabular}{|c|c|c|c|c|c|c|}
\hline Measurement & $m_{1}[g]$ & $m_{2}[g]$ & $m_{3}[g]$ & $m_{4}[g]$ & $m_{5}[g]$ & Meanvalue [g] \\
\hline \multicolumn{7}{|c|}{ Oil after use } \\
\hline Glass beak & 175.07 & 175.05 & 175.06 & 175.09 & 175.08 & 175.07 \\
\hline $\begin{array}{l}\text { Glass beak } \\
+600 \mathrm{ml} \text { oil }\end{array}$ & 686.79 & 686.8 & 686.79 & 686.84 & 686.83 & 686.81 \\
\hline \multicolumn{7}{|c|}{ New oil } \\
\hline Glass beak & 179.87 & 179.86 & 179.87 & 179.86 & 179.86 & 179.864 \\
\hline $\begin{array}{l}\text { Glass beak } \\
+600 \mathrm{ml} \text { oil }\end{array}$ & 679.79 & 679.79 & 679.79 & 679.79 & 679.79 & 679.79 \\
\hline
\end{tabular}

Table 3 shows the values of the calculated standard deviation and the coefficient of variability of viscosity measurement results [11-12].

Comparison of the results obtained from the tested unused and used oil samples is presented in table 4. Figure 2 illustrates the dependence of kinematic viscosity of the analyzed oils on temperature [11-12].

Based on the analysis of the oil kinematic viscosity dependence on temperatures (fig. 2) one can say that viscosity characteristic in a function of temperature is similar for both samples. The values of kinematic viscosity increase along with the temperature decrease.

Table 2. Results of kinetic viscosity measurement.

\begin{tabular}{|c|c|c|c|c|c|c|}
\hline $\begin{array}{c}\text { Measurement } \\
\text { Temperature }\end{array}$ & $\begin{array}{c}\mathbf{p}_{1} \\
{\left[\mathrm{~mm}^{2} / \mathbf{s}\right]}\end{array}$ & $\begin{array}{c}\mathbf{p}_{2} \\
{\left[\mathbf{m m}^{2} / \mathbf{s}\right]}\end{array}$ & $\begin{array}{c}\mathbf{p}_{3} \\
{\left[\mathbf{m m}^{2} / \mathbf{s}\right]}\end{array}$ & $\begin{array}{c}\mathbf{p}_{4} \\
{\left[\mathbf{m m}^{2} / \mathbf{s}\right]}\end{array}$ & $\begin{array}{c}\mathbf{p}_{5} \\
{\left[\mathbf{m m}^{2} / \mathbf{s}\right]}\end{array}$ & $\begin{array}{c}\text { Meanvalue } \\
{\left[\mathbf{m m}^{2} / \mathbf{s}\right]}\end{array}$ \\
\hline & Oil after use \\
\hline
\end{tabular}




\begin{tabular}{|c|c|c|c|c|c|c|}
\hline $21{ }^{\circ} \mathrm{C}$ & 169.5 & 171.1 & 170.1 & 172.2 & 172.8 & 17114 \\
\hline $40{ }^{\circ} \mathrm{C}$ & 63.3 & 63.4 & 63.1 & 64.8 & 65 & 63.92 \\
\hline $100{ }^{\circ} \mathrm{C}$ & 12.1 & 12.2 & 13 & 12.5 & 11.9 & 12.34 \\
\hline$-20^{\circ} \mathrm{C}$ & 6259 & 6280.2 & 6290.2 & 6258.3 & 6250.1 & 6267.56 \\
\hline \multicolumn{7}{|c|}{ New oil } \\
\hline $21{ }^{\circ} \mathrm{C}$ & 117.4 & 116.2 & 115.3 & 118.8 & 118,6 & 117.26 \\
\hline $40^{\circ} \mathrm{C}$ & 53.6 & 50 & 53.1 & 51.6 & 43 & 50.26 \\
\hline $100^{\circ} \mathrm{C}$ & 11 & 10.9 & 10.8 & 10.5 & 11 & 10.84 \\
\hline$-19{ }^{\circ} \mathrm{C}$ & 2143.6 & 2156.2 & 2187.6 & 2196.5 & 2140.9 & 2164.96 \\
\hline
\end{tabular}

Table 3. Value of standard deviation and coefficient of variability of viscosity measurement results.

\begin{tabular}{|c|c|c|}
\hline $\begin{array}{c}\text { Temperature } \\
{\left[{ }^{\circ} \mathrm{C}\right]}\end{array}$ & $\begin{array}{c}\text { Standard deviation } \\
{\left[\mathbf{m m}^{2} / \mathbf{s}\right]}\end{array}$ & $\begin{array}{c}\text { Variability coefficient } \\
{[\%]}\end{array}$ \\
\hline \multicolumn{3}{|c|}{ Oil after use } \\
\hline $21{ }^{\circ} \mathrm{C}$ & 1.383112432 & 0.808176015 \\
\hline $40{ }^{\circ} \mathrm{C}$ & 0.903880523 & 1.414080918 \\
\hline $100{ }^{\circ} \mathrm{C}$ & 0.427784993 & 3.466653101 \\
\hline$-20{ }^{\circ} \mathrm{C}$ & 16.85387196 & 0.268906432 \\
\hline & New oil \\
\hline $21{ }^{\circ} \mathrm{C}$ & 1.512613632 & 1.289965574 \\
\hline $40{ }^{\circ} \mathrm{C}$ & 4.295113503 & 8.545788903 \\
\hline $100{ }^{\circ} \mathrm{C}$ & 0.207364414 & 1.912955844 \\
\hline$-19{ }^{\circ} \mathrm{C}$ & 25.58911878 & 1.181967278 \\
\hline
\end{tabular}

The results of measurements for the sample of the used oil are significantly different from those provided for the virgin oil in the entire range. A distinct increase in the used oil kinematic viscosity as compared to the virgin oil was observed for negative temperatures. Although the post-use oil temperature was lower only by $1^{\circ} \mathrm{C}$ than the temperature of the virgin oil, the value of the used oil kinematic viscosity was higher by as much as 4102.6 $\mathrm{mm}^{2} / \mathrm{s}$. The value of viscosity index for the used oil dropped as compared to the result obtained from a viscosity analysis of the unused oil.

Table 4. Presentation of the results obtained from tests of the oils.

\begin{tabular}{|c|c|c|}
\hline Testedcharacteristic & $\begin{array}{c}\text { Result of post-use oil } \\
\text { measurement }\end{array}$ & $\begin{array}{c}\text { Result of new oil } \\
\text { measurement }\end{array}$ \\
\hline density & $0.8529 \mathrm{~g} / \mathrm{cm}^{3}$ & $0.8332 \mathrm{~g} / \mathrm{cm}^{3}$ \\
\hline $\begin{array}{c}\text { Kinematic viscosity in } \\
\text { temperature } 21^{\circ} \mathrm{C}\end{array}$ & $171.14 \mathrm{~mm}^{2} / \mathrm{s}$ & $117.26 \mathrm{~mm}^{2} / \mathrm{s}$ \\
\hline $\begin{array}{c}\text { Kinematic viscosity in } \\
\text { temperature } 40^{\circ} \mathrm{C}\end{array}$ & $63.92 \mathrm{~mm}^{2} / \mathrm{s}$ & $50.26 \mathrm{~mm}^{2} / \mathrm{s}$ \\
\hline
\end{tabular}




\begin{tabular}{|c|c|c|}
\hline $\begin{array}{c}\text { Kinematic viscosity in } \\
\text { temperature } 100^{\circ} \mathrm{C}\end{array}$ & $12.34 \mathrm{~mm}^{2} / \mathrm{s}$ & $10.84 \mathrm{~mm}^{2} / \mathrm{s}$ \\
\hline $\begin{array}{c}\text { Kinematic viscosity in } \\
\text { negative temperature }\end{array}$ & $\begin{array}{c}6267.56 \mathrm{~mm}^{2} / \mathrm{s} \\
-20^{\circ} \mathrm{C}\end{array}$ & $\begin{array}{c}2164.96 \mathrm{~mm}^{2} / \mathrm{s} \\
-19^{\circ} \mathrm{C}\end{array}$ \\
\hline Viscosity index & 194.96 & 214.02 \\
\hline
\end{tabular}

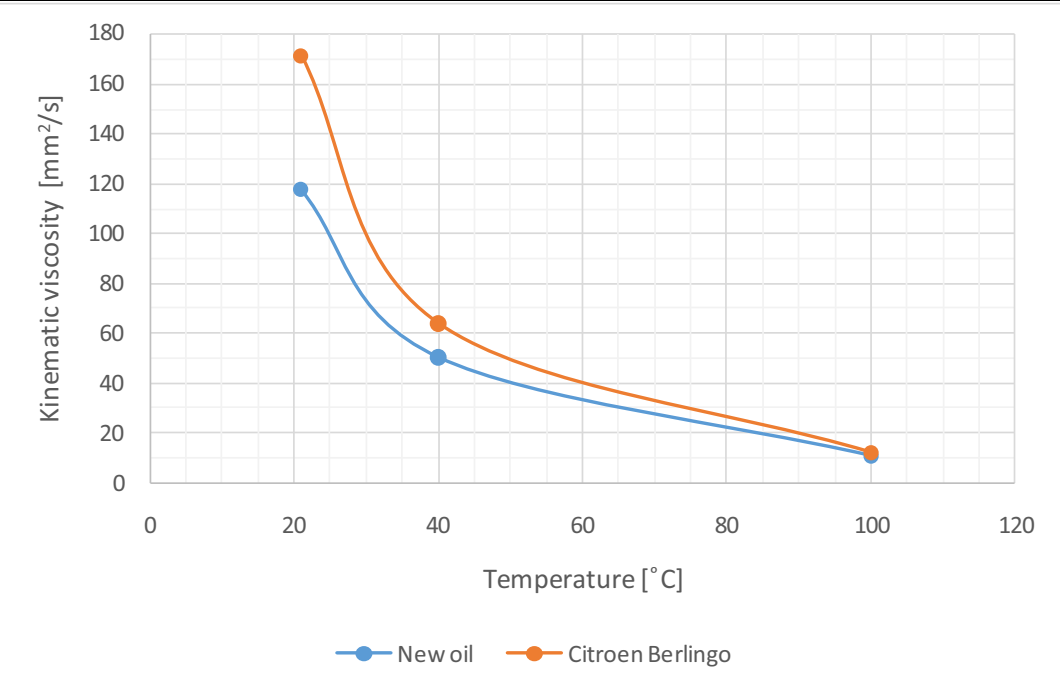

Fig. 2. Dependence between kinematic viscosity and the oil kinematic temperature.

No disturbing changes were observed during paper chromatography (fig. 3). The oil disintegrates into fractions in a proper way but it contains a lot of contaminants. The boundary of the diffusion and the stain nucleus is not visible. The blot test did not reveal the presence of water or fuel in the oil sample.

In order to illustrate the state of a Citroen Berlingo drive unit used for tests, figures 4 to 6 show photographs taken during the tests [11-12].

It seems that the tests results have provided the basis to formulate a conclusion of a universal character in the form of a recommendation. It appears to be advisable for vehicles with significant mileages to apply engine rinsing during a periodic oil change in order to remove the residues left on its elements.

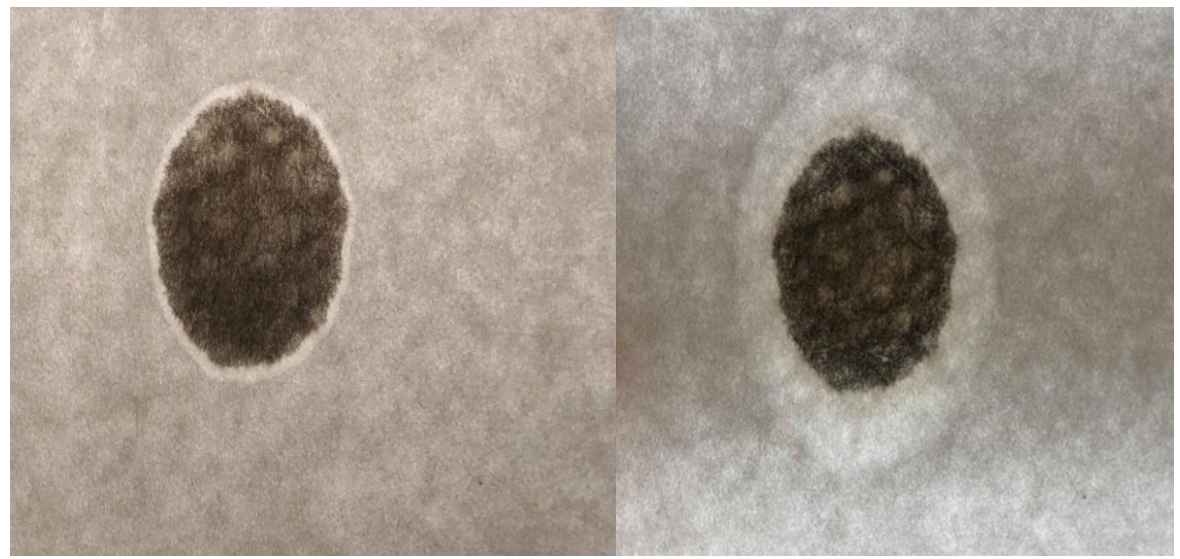

Fig. 3. A picture of chromatography on a paper after $24 \mathrm{~h}$ and $72 \mathrm{~h}$ [11-12]. 


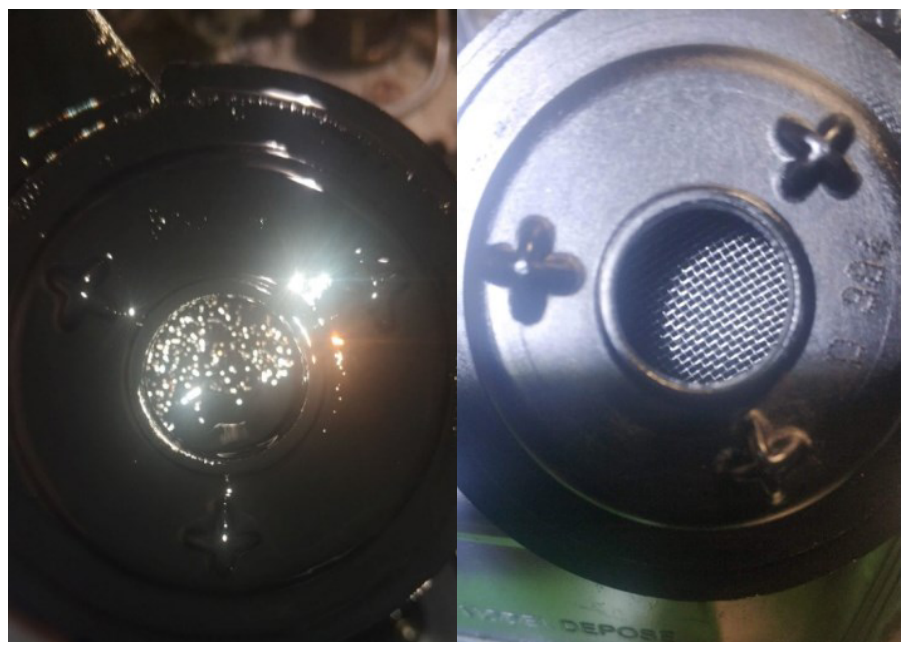

Fig. 4. Filter of the oil suction pipe before and after cleaning [11-12].

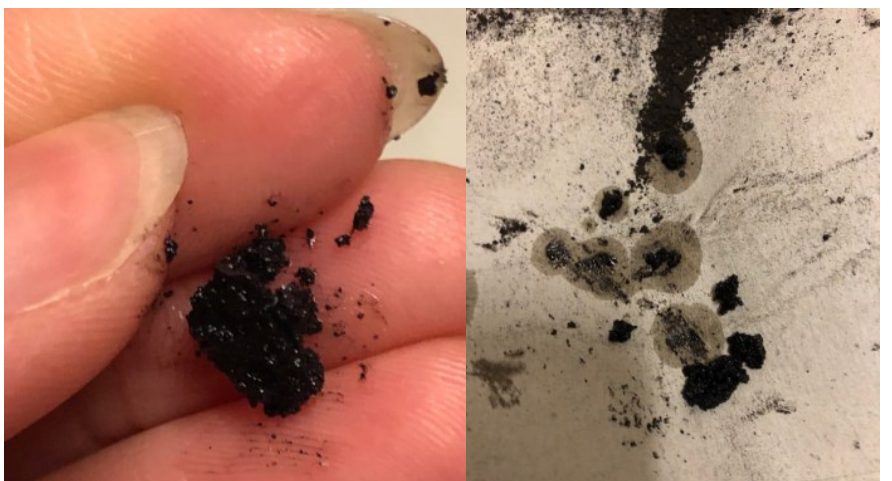

Fig. 5. Pollution of the oil sump bottom and filter of the sucking pipe [11-12].

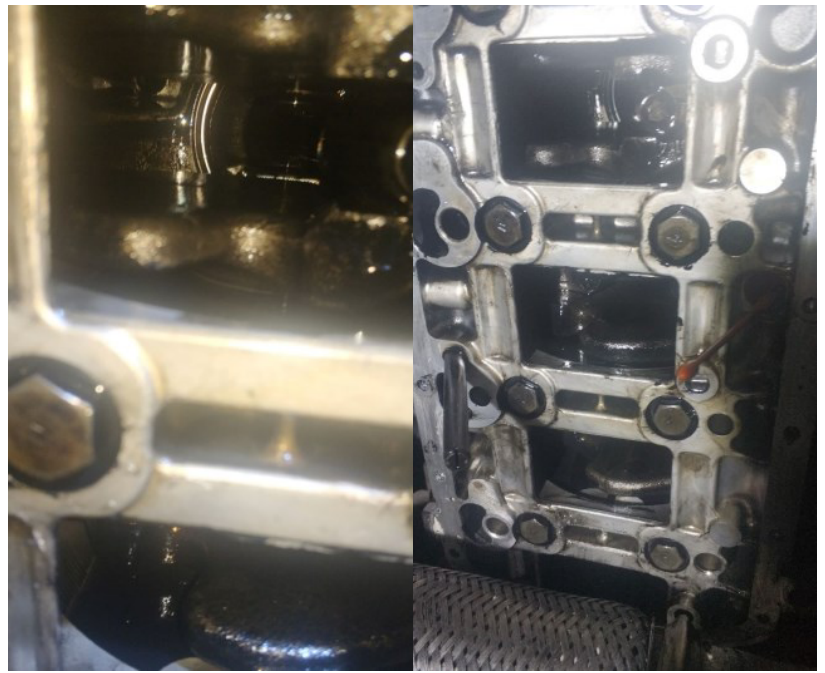

Fig. 6. The engine bottom [11-12]. 


\section{Conclusions}

Comparison of the results of tests of used oils with virgin oils indicate that value changes in the oil rheological parameters can depend on the state of the engine which is indicated by the results of tests obtained for the oil used in a Citroen Berlingo car.

Low values of the calculated standard deviation and variability coefficient for the measurement results indicate high reproductivity of the obtained measurement results.

Paper chromatography (that is the blot or stain test), can be used, among others, to find out whether the tested lubricating oil contains water or fuel.

\section{References}

1. W. Urzędowska, Z. Stępień, Selectes issues concerning motor lubricant viscosity changes during operation. NAFTA-GAZ, December, Poland (2012)

2. W. Zwierzycki, Fuels, Oils, Motor opertional liquids. Oil Refinery 'Glimar" S.A. Editorial Office in Gorlice, Gorlice (1998)

3. A. M. Ryniewicz, Ł. Bojko, T.Madej, Assessment of motor oil viscosity with the use of rotary viscometer, Scientific bulletins of Silesian University of Technology, Transport, Vol. 83, No. 1904 (2014)

4. A. Ambrozik, J. Jakóbiec, G. Wysopal, Basic tendencies in motor lubricant changes. Buses: technology, operation, transport systems, No. 12 (2011)

5. B. Landowski, Ł. Muślewski, M. Pająk, O. Polishchuk, Method for initial assessment of unit costs of public city transport means operation, MATEC Web of Conferences 182, 01010 (2018), 17th International Conference Diagnostics of Machines and Vehicles, pp.1-7 (2018), https://doi.org/10.1051/matecconf/201818201010

6. B. Landowski, D. Perczyński, Ł. Muślewski, P. Kolber, Economic aspects of a city transport means purchase. Proceedings of 58th International Conference of Machine Design Departments - ICMD 2017, Publisher: Czech University of Life Sciences Prague, Czech Republic, pp. 194-199 (2017)

7. B. Landowski, Ł. Muślewski, Decision model of an operation and maintenance process of city buses, Proceedings of 58th International Conference of Machine Design Departments - ICMD 2017, Publisher: Czech University of Life Sciences Prague, Czech Republic, pp. 188-193 (2017)

8. B. Landowski, Numerical simulation of the process of a technical object state changes. Journal of KONBiN 45(2018), pp. 247-266 (2018)

9. B. Landowski, Ł. Muślewski, Numerical simulation of stochastic process as a model of technical object state changes. Engineering Mechanics 2018, 24nd International Conference, may 14 - 17, 2018, Svratka, Czech Republic, Book of full texts, Institute of Theoretical and Appiled Mechanics of the Czech Academy of Sciences, Prague, pp. 485-488 (2018)

10. B. Landowski, D. Perczyński, P. Kolber, Ł. Muślewski, An example of Markov model of technical objects maintenance process. Engineering Mechanics 2016, 22nd International Conference, may 9 - 12, 2016, Svratka, Czech Republic, Book of full texts, Institute of Thermomechanics Academy of Sciences of the Czech Republic, pp. 346-349 (2016)

11. B. Landowski, M. Baran, Analysis of viscosity of selected motor lubricants. University of Science and Technology materials, Department of Maintenance and Transport, Bydgoszcz, Poland (2019)

12. M. Baran, Analysis of selected characteristics of engine oils. Diploma thesis, University of Science and Technology, Bydgoszcz, Poland (2019) 